\title{
Development of a Chill Unit Accumulation System for Site-Specific Estimation of Grape Dormancy Release Date
}

\author{
Kwang S. KMM", Dong-Geun CHOI ${ }^{* *}$, Uran CHUNG ${ }^{* * *}$, and Jin I. YUN ${ }^{* * *}$ \\ "Department of Plant Pathology, Iowa State University, Ames, IA, USA. \\ "Jeonbuk Agricultural Research and Extension Service, Iksan, Korea \\ *.* Department of Ecosystem Engineering, Kyung Hee University, Suwon, Korea
}

\begin{abstract}
A chill unit has been used to estimate the chilling requirement for dormancy release and risk of freezing damage. A system that calculates chill units was developed to obtain site-specific estimates of dormancy release date for grapes and evaluated in Baekgu-myun near Gimje City, Jeonbuk, Korea from September 2002 to March 2003. The system utilized daily minimum and maximum temperature maps generated from spatial interpolation and temperature correction for topography. Hourly temperature was temporally interpolated from the daily data using a sine-exponential equation. Hourly chill units were determined from sigmoid, reverse sigmoid, and negatively increasing sigmoid functions based on temperature ranges and summed for $24 \mathrm{~h}$. Cumulative daily chill units obtained from measurements did not increase until 20 October 2002, which was used as a start date for accumulation to estimate the dormancy release date. As a result, a map of dormancy release date in the study area was generated, assuming 800 chill units as a threshold for the chilling requirement. The chill unit accumulation system, which was implemented using Microsoft Visual Basic and C++ (Microsoft, Redmond, WA, USA), runs in the Windows environment with ArcView (ESRI Inc., Redlands, CA, USA).
\end{abstract}

Key words: Chill Unit, Dormancy, Fruit trees, Phenology, Spatial analysis

\section{Introduction}

Temperate zone fruit trees rely on a certain period of dormancy or rest period during winter for flowers and leaf buds to develop normally. Once vegetative and fruiting buds have entered dormancy, their growing tips are protected from lethally low temperature and buds will not grow in response to mid-winter warm spells. When enough chilling accumulates, dormancy is completely released and the buds are ready to grow in response to warm temperatures. After release of dormancy, the cold tolerance weakens abruptly (Faust, 1989). Therefore, frosts or low temperatures can destroy flowering buds and reduce yield potential under accelerated development conditions due to high temperature during spring.

Estimation of a date on which dormancy is completely released benefits growers by providing a sense of the orchard management practice. It is possible to estimate the dormancy release dates of fruit trees by quantifying the degree of chilling during winter. Estimation of depth of dormancy may also make it possible to develop a warning system that warn of the risk of freezing damage in low temperature forecast, since freezing tolerance is related to the level of fulfillment of the chilling requirement (Faust, 1989).

Chill units have been used to estimate the depth of dormancy using hourly temperature data (Seely, 1996). The Utah model, which introduces the concept of relative chilling effectiveness and negative chilling accumulation, has been used to estimate chill units
(Richardson et al., 1974). The Utah model, however, requires complex computation and hourly air temperature as input data that are usually unavailable to growers. Furthermore, since chilling requirements differ by varieties and cultivars, estimation of chill units should be site-specific. Therefore, systematic processes are required to estimate hourly weather data and calculate chill units at a specific site in order to provide useful information to each grower within an area.

Since it is relatively easy to obtain daily maximum and minimum temperatures, temporal interpolation can be used to estimate hourly air temperature from them (Valentini et al., 2001; Egea et al., 2003). By using a simple spatial interpolation approach, e.g., inverse distance weight (IDW) method, it is possible to estimate weather variables with acceptable accuracy under a flat terrain condition. Complex topography within an area, however, may make it challenging to estimate air temperature accurately, which requires various corrections of interpolated temperature data. In this study, these approaches were integrated into a single system to estimate spatial variation of accumulated chill units and dormancy release date. The objective of our study was to develop a software system that estimates weather data using temporal and spatial interpolation, calculates chill units, and predicts dormancy release date at site-specific scale $(10 \mathrm{~m})$ within a certain area. 


\section{Materials and Methods}

\subsection{Study site}

Baekgu-myun, Jeonbuk, Korea (35 5'N, 126 45'E), has an undulated terrain (Fig. 1). Freezing damage occasionally occurred at vineyards in this area during winter. An area in which vineyards were densely located was chosen to estimate chill units sitespecifically. Weather variables were measured at automated weather stations (AWS) that the Korea Meteorological Administration (KMA) managed. The weather stations located at Gunsan, Jeonju, Buan, and Jeongeub, which were within a $50 \mathrm{~km}$ radius from Baekgu-myun.

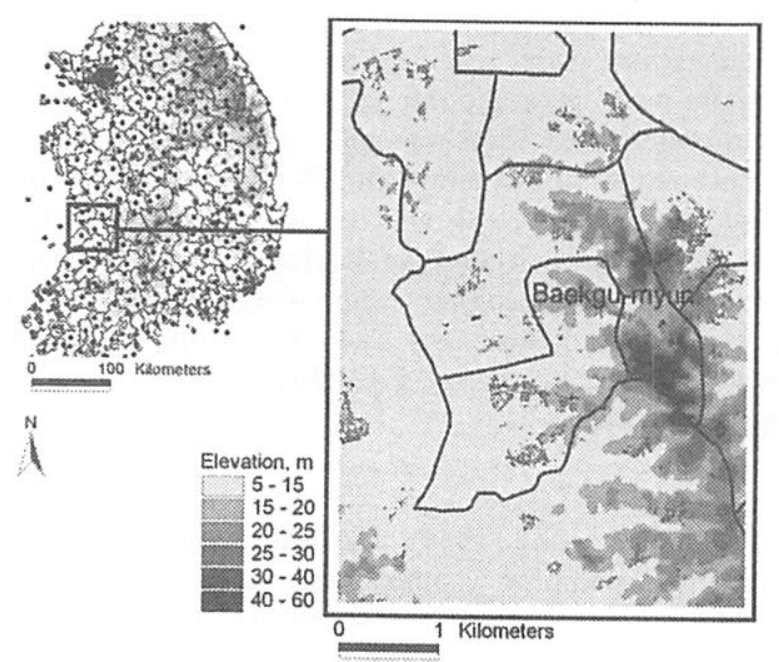

Fig. 1. Location map of the study area with the agrometeorological station sites.

A digitized map (5,000:1 scale) was obtained from National Geographic Information Institute (NGII, Korea) to generate a TIN (triangulated irregular network) surface from a contour layer and convert it to the DEM (digital elevation model) at a 10-m resolution. A virtual terrain of the study area, which is required for spatial interpolation of air temperature, was generated by IDW interpolation at $250-\mathrm{m}$ resolution using elevation data of four weather stations. The elevation deviation was calculated by subtracting sea level elevation of the virtual terrain from that of the 10 -m resolution DEM.

\subsection{Spatial interpolation of temperature}

Daily maximum and minimum temperatures recorded at weather stations were obtained from 1 September 2001 to 21 March 2002, which was a total of 212 days. They were spatially interpolated within the study area using IDW interpolation, which generated a total of 424 grids of maximum and minimum temperature, using ArcGIS (ESRI, Redlands, CA).

After performing spatial interpolation of these temperatures, correction was made using temperature lapse rates and topography-climate models. For corrections of interpolated maximum temperature, we used the BioSIM model of the Canadian Forestry Service (Regniere et al., 1996; Chung et al., 2003). The BioSIM requires a so-called "overheating index" $(\mathrm{OHI})$, which can be estimated by integrating incoming solar radiation on slopes from 1100 to 1500 LST. A model that adjusts effects of nocturnal cold air accumulation as well as thermal belt was utilized to adjust interpolated daily minimum temperature (Chung et al., 2002).

\subsection{Temporal interpolation of temperature}

Since-exponential equation (Patron and Logan, 1981) was used to interpolate hourly air temperature from daily maximum and minimum temperatures.

Air temperature at a given time $i$ during daytime was calculated as follows:

$$
T_{i}=\left(T_{x}-T_{N}\right) \cdot \sin \left(\frac{\pi \cdot(m-b)}{Y+2 a}\right)+T_{N}
$$

where $\mathrm{T}_{\mathrm{X}}=$ daily maximum temperature $\left({ }^{\circ} \mathrm{C}\right), \mathrm{T}_{\mathrm{N}}=$ daily minimum temperature $\left({ }^{\circ} \mathrm{C}\right), \mathrm{Y}=$ day length $(\mathrm{h})$, $\mathrm{m}=\mathrm{a}$ time period from the hour when minimum temperature was observed to sunset (h), a and $b=1.86$ and 0.17 , respectively.

Air temperature during night was calculated as follows:

$$
T_{i}=\left(T_{s}-T_{N}\right) \cdot \exp \left(-\frac{c \cdot n}{Z}\right)+T_{N}
$$

where $\mathrm{S}=$ time at sunset, $\mathrm{n}=\mathrm{a}$ time period after sunset until minimum temperature was measured in next day (h), $\mathrm{Z}=$ duration of night (h), and $\mathrm{c}=2.20$.

\subsection{Estimation of chill unit}

Seely (1996) suggested sigmoid, reverse sigmoid and negatively increasing sigmoid curves depending on a temperature range based on the Utah model. Equations that fit such curves to calculate chill unit were derived using SAS NLIN (SAS Institute, Cary, $\mathrm{NC}$ ), which were expressed as follows:

$$
\begin{array}{ll}
y=0 & T_{i} \leq-2 \\
y=\frac{1}{1+28\left(T_{i}+2\right)^{-3}} & -2<T_{i} \leq 6 \\
y=1-\frac{1}{1+28\left(14-T_{i}\right)^{-3}} & 6<T_{i} \leq 14 \\
y=\frac{-1}{1+28\left(T_{i}-14\right)^{-3}} & T_{i}>14
\end{array}
$$

The chill unit accumulation system software, termed the CUMAP, was implemented using Visual $\mathrm{C}++$ and Visual Basic (Microsoft, Redmond, WA, USA) to estimate chill unit and release date of dormancy. 


\section{Results and Discussion}

Since the chilling requirement for grapes (cv. Campbell Early) was unavailable, its value was estimated by accumulating chill units. After analyzing estimated chill units, it was clear that the accumulated chill unit did not increase until 20 October 2002 (Fig. 2). Therefore, the date was considered as the onset of dormancy. Growers conventionally assumed that dormancy released on mid-January and late-January in Kunsan and Buan, respectively.

To estimate chilling requirements, chill units were accumulated from the onset of dormancy to the assumed dormancy release date, which resulted in 800 chill units as a threshold to release dormancy (Fig. 3).

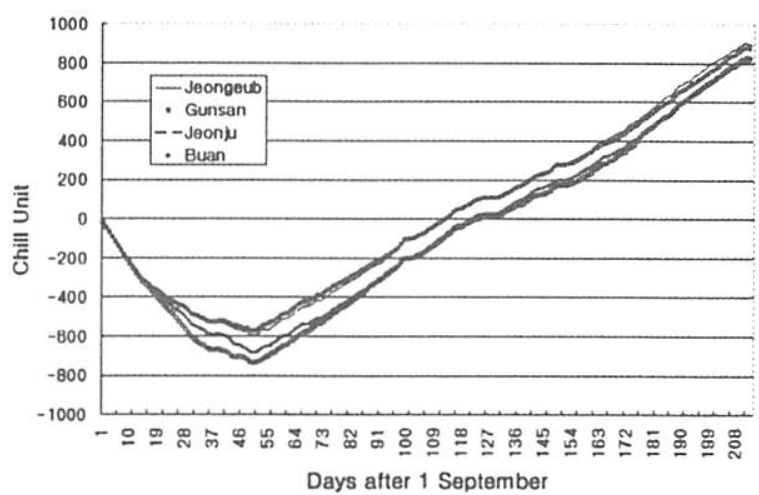

Fig. 2. Temporal march of Chill Unit accumulation at 4 sites with the KMA offices from 1 September 2002 to $31 \mathrm{March} 2003$. Initially decreasing curves rebound at the lowest point on a specific date (20 October in this 2002 case) and this point is believed to be the beginning of endo-dormancy.

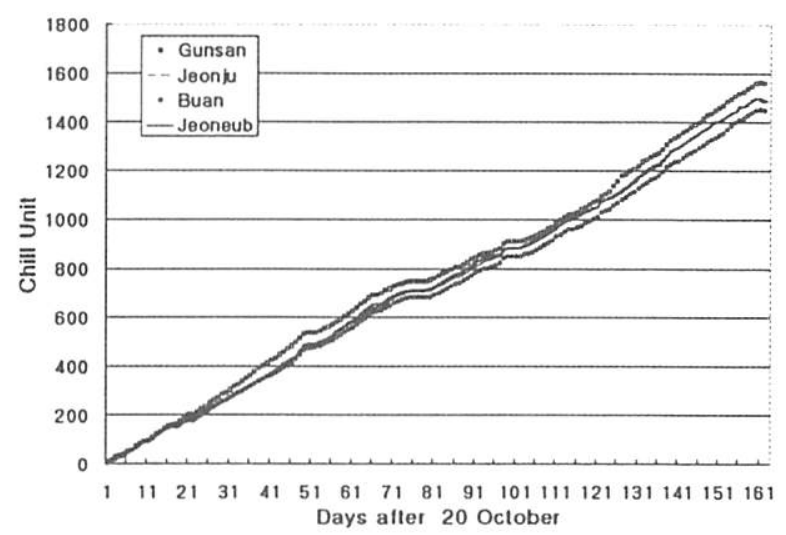

Fig. 3. Chill Unit accumulation since 20 October at 4 sites during the 2002-2003 winter season.

Under the assumption that the chilling requirement of Campbell Early was 800, dormancy release was earliest in Kunsan, at the middle in Junju and Jungeub, and most delayed in Buan.

Maps that the CUMAP generated indicated high spatial variability of dormancy release date within the study area (Fig. 4). For example, at B2, dormancy released $>10$ days earlier than for $\mathrm{B} 3$, which was about 300m distant from B2. The CUMAP made it possible to obtain spatial distribution of cumulative chill units using weather data measured at a relatively small number of weather stations. The CUMAP can also be utilized as a practical tool to study the relationship between depth of dormancy of fruit trees and climate. Furthermore, it may be possible to estimate the degree of freezing tolerance by predicting the fulfillment of chilling requirements using the CUMAP, which would provide useful information to prepare management approaches against freezing damage.

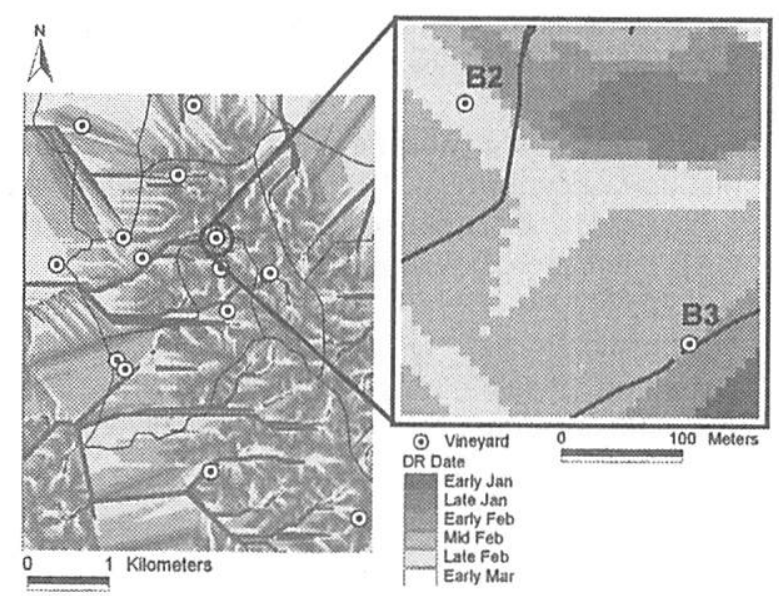

Fig. 4. Spatial distribution of the predicted dates for dormancy release in Campbell Early grape variety (assuming 800 Chill Units for chilling requirement) in the Baekgu region. Insert is a part of zoomed image.

\section{Acknowledgements}

This study was supported by the Cooperative Research Initiative Project by the Rural Development Administration (RDA) of Korea.

\section{References}

Balandier, P., Bonhomme, M., Rageau, R., Capitan, F., and Parisot, E., 1993: Leaf bud endodormancy release in peach trees: evaluation of temperature models in temperate and tropical climates. Agricultural and Forest Meteorology 67, 95-113.

Chung, U., Seo, H. H., Hwang, K. H., Hwang, B. S., and Yun, J. I., 2002: Minimum temperature mapping in complex terrain considering cold air drainage. Korean Journal of Agricultural and Forest Meteorology 4(3), 133-140.

Chung, U., Hwang, B. S., Seo, H. H., and Yun, J. I., 2003: Relationship between exposure index and overheating index in complex terrain. Korean Journal of Agricultural and Forest Meteorology 5(3), 133-140.

Egea, J., Ortega, E., Martines-Gomez, P., and Dicenta, F., 2003: Chilling and heat requirement of almond cultivars for flowering. Environmental and Experimental Botany 50, 79-85. 
Faust, M., 1989: Resistance of fruit trees to cold. In Physiology of Temperate Zone Fruit Trees. John Wiley and Sons, pp.307-331.

Parton, W. J., and Logan, J. A., 1981: A model for diurnal variation in soil and air temperature. Agricultural and Forest Meteorology 23, 205-216.

Regniere, J., Cooke, B., and Bergeron, V., 1996: BioSIM: A Computer-Based Decision Support Tool for Seasonal Planning of Pest Management Activities. User's Manual. Canadian Forest Service Info. Rep. LAU-X-116. 50pp.

Richardson, E. A., Seely, S. D., and Walker, D. R., 1974: A model for estimating the completion of rest for Redhaven and Elberta peach trees. HortScience 10, 559-560.

Seely, S. D., 1996: Modeling climatic regulation of bud dormancy. In G. A. Lang (ed.) Plant Dormancy - Physiology, Biochemistry and Molecular Biology. CAB International, Wallingford, U.K., 361-376.

Valentini, N., Me, G., and Ferrero, R., 2001: Use of bioclimatic indexs to characterize phenological phase of apple varieties in northern Italy. International Journal of Biometeorology 45, 191195. 